\title{
Manifestation of Key Molecular Genetic Markers in Pharmacocorrection of Endogenous Iron Metabolism in MCF-7 and MCF-7/DDP Human Breast Cancer Cells
}

\author{
Vasyl’ Chekhun, Natalia Lukianova, Dmytro Demash, Tetiana Borikun, \\ Svyatoslav Chekhun, Yulia Shvets \\ Department of Mechanisms of Antitumor Therapy, R.E. Kavetsky Institute of Experimental Pathology, \\ Oncology and Radiobiology, NAS of Ukraine, Kyiv, Ukraine \\ Email: chekhun@onconet.kiev.ua
}

Received August 1, 2013; revised September 1, 2013; accepted September 8, 2013

Copyright (C) 2013 Vasyl' Chekhun et al. This is an open access article distributed under the Creative Commons Attribution License, which permits unrestricted use, distribution, and reproduction in any medium, provided the original work is properly cited.

\begin{abstract}
Effects of the nanocomposite and its components (magnetic fluid, cisplatin) on the level of endogenous iron exchange and the key links of genetic and epigenetic regulation of apoptotic program of sensitive and resistant MCF-7 cells were examined. We showed genetic and epigenetic mechanisms of action of nanocomposite of magnetic fluid and cisplatin. Nanocomposite caused elevation of number of cells in apoptosis in sensitive and especially resistant MCF-7 cells compared to cisplatin alone. It was proved that impact of nanocomposite on MCF-7/S and MCF-7/DDP cells caused more significant changes in expression of apoptosis regulators p53, Bcl-2 and Bax. We also suggested that changes in endogenous iron homeostasis and activation of free radical processes caused significant impact on apoptosis. Those changes included changes in methylation and expression of transferrin, its receptors, ferritin heavy and light chains (predominantly in resistant cell line), which caused activation of free radical synthesis and development of oxidative stress. We also showed that nanocomposite impact resulted into significant changes in expression of miRNA-34a and miRNA-200b, which regulated apoptosis, cell adhesion, invasion and activity of ferritin heavy chains gene. Thus, use of nanocomposite containing cisplatin and ferromagnetic as exogenous source of $\mathrm{Fe}$ ions caused changes of endogenous iron levels in sensitive and resistant cells allowing to increase specific activity of cytostatics and overcome factors, which promoted MDR development. Pharmacocorrection of endogenous iron metabolism allowed increasing antitumor activity of cisplatin and overcoming drug resistance.
\end{abstract}

Keywords: Nanocomposite; Iron Metabolism; Apoptosis; ROS; Drug Resistance; Breast Cancer Cells

\section{Introduction}

A new round of research in the field of tumor cells' biology significantly changed the common view not only about the latent period of malignancy, its clinical and morphological classification, characteristics of the proliferative and metastatic potential, but also the selection of treatment, the criteria for disease-free and overall patients' survival.

If, for example, we consider only the cellular heterogeneity and microenvironment in tumor tissue, then modern immunohistochemical subtypes from basal and luminal A/B to "triple negative" breast cancer are just like surrogate analogues of real molecular genetic characteristics that can be significant for clinical oncology $[1,2]$.

One of the basic reasons for the heterogeneity of tumor tissue is the genetic and genomic instability caused by DNA sequence violations and rearrangement of chromosomes that determine the level of oncogenes and expression of tumor suppressors $[3,4]$.

Increased expression of certain genes and reduction of others constantly change their dynamic balance, which determines not only the degree of heterogeneity, but also the level of sensitivity to therapy [5].

The emergence of these changes is predominantly associated with violation of the program of epigenetic regulation of tumor cell, which is accompanied by general hypomethylation and hypermethylation of promoters of individual genes. The rapid progress in studying of epigenetic regulation mechanisms of gene expression revealed regulatory role of small miRNA molecules, 
which regulate post-translational process at the level of protein synthesis [6-8].

However, significant progress in understanding of the nature of the malignant process does not produce the expected results in terms of early diagnostics, effective treatment and life quality improvement of cancer patients.

The need to improve clinical outcomes dictates a paradigm shift in the system of accumulation, analysis and interpretations of our knowledge.

Recent fundamental studies on metabolism of endogenous and exogenous iron in normal and tumor cells showed high degree of $\mathrm{Fe}$ ions integration into biological systems of human organism that offered a prospect of new markers and targets identification for development of antineoplastic agents. Iron is an essential element for cell growth and division because it exists in the structure of active sites of various proteins and takes part in many different reactions. Iron ions property to change quickly its valence from $\mathrm{Fe}^{2+}$ to $\mathrm{Fe}^{3+}$ made them vitally important in such reactions as DNA synthesis, oxygen transport, energy metabolism, cell cycle control, etc. At the same time its high reactivity makes it rather toxic compound, which causes hydroxyl radicals production. H. Fenton showed that during interaction with different reductants inside, the cell $\mathrm{Fe}^{3+}$ turned into $\mathrm{Fe}^{2+}$ [9]. It is known that formed reactive oxygen species interact with lipids, proteins, DNA, causing mutations and cell damage, which can initiate malignant transformation. Such unfavorable scenario for normal cell might become an optimal finding for selective damage of tumor cell. One of the unique properties of tumor cells is their increased affinity to $\mathrm{Fe}^{2+}$ ions [10-12]. It is important that intracellular Fe depot exists in forms of free/bound iron pools and ferritin. In healthy adults about $25 \%-30 \%$ of $\mathrm{Fe}$ ions are connected with ferritin, thus preventing the development of toxic effects caused by this metal [13]. In normal cells in cases of supplement needs, iron is escaped from depot and is transported out of the cells by ferroportin and serum transferrin [14]. High intracellular Fe level causes ferritin translation, while its deficiency blocks this process [15]. Due to potential toxicity and possibility of reactive oxygen species (ROS) generation, the Fe level in organism is strictly controlled [16]. Instead, this is not typical for tumor cell. For activation of DNA synthesis it elevates ferritin levels, including multidrug resistance (MDR) formation $[12,17]$. And this is the second paradox. The fact of immunological identity between ferritin and autocrine growth factor secreted by leucosis cells is very interesting [18].

Today it is well known that besides the role in DNA synthesis, Fe ions affect the expression of proteins that are involved in cell cycle regulation, cell proliferation and angiogenesis and participate in the formation of cells' metastatic potential. Numerous studies have proved the role of iron in the anti-tumor effect of cytotoxics $[19,20]$. A new wave of interest in the investigation of $\mathrm{Fe}$ ions and iron-containing proteins greatly expanded understanding of their dominant role in vital functions of both normal and tumor cells [12]. Today, it is clearly possible to speak about a whole family of iron-containing proteins, which define the system of cell activity and can be considered, on the one hand, as biological markers of tumor process and, on the other hand, as promising targets for anti-tumor therapy. It is known that $\mathrm{Fe}$ ions, like most cytotoxic agents, are capable to initiate apoptosis in cell lines of different origin. At the same time different chelators and donators of iron ions are being discovered and actively studied [21,22].

At the present stage of development of theoretical, experimental and clinical oncology considerable interest is focused on the sources of iron in the form of nanomaterials, first, as a potential delivery vector for cytostatics; second, as an exogenous modifier of endogenous iron metabolism; and third, as a factor of selective accumulation and overcoming of resistance to anti-tumor drugs (ATDR).

The aim of this study was to examine the effect of the nanocomposite (NC) and its components (magnetic fluid (MF), cisplatin (DDP)) on the level of endogenous iron exchange and the key links of genetic and epigenetic regulation of apoptotic program of sensitive and resistant MCF-7 cells.

\section{Materials and Methods}

The investigation was carried out in vitro on cultures of MCF-7 human breast cancer cells, sensitive (MCF-7/S) and resistant to DDP (MCF-7/DDP). The cells of original line (sensitive to ATDR) were cultivated in modified culture medium Dulbecco ISCOVE (Sigma, Germany) with adding of $10 \%$ of fetal bovine serum (Sangva, Ukraine) at the temperature of $37^{\circ} \mathrm{C}$ and $\mathrm{CO}_{2}$ concentration of $5 \%$. The cells have been reseeded twice a week with density $2-4 \times 10^{4}$ cells $/ \mathrm{cm}^{2}$. We obtained a variant of this line resistant to DDP (MCF-7/DDP) by growing of cells in culture medium with adding of rising concentrations of DDP. Every two months studied cells were analyzed in order to determine the level of their resistance with 3-(4,5-dimethylthiazol-2-1)-2,5-diphenyltetrazolium bromide (MTT viability test). On the moment of investigation the level of resistance of MCF-7/DDP cells was 4 .

\subsection{MTT Assay}

After incubation period $10 \mu \mathrm{l}$ of MTT were added into every well of 96-well plate. Cells were incubated at $37^{\circ} \mathrm{C}$ in humid atmosphere for 3 hours and then centrifuged (1500 rpm for $5 \mathrm{~min}$ ). Violet crystals of formazan were visually detected on the bottom of wells. After removal of 
the supernatant $50 \mu$ of DMSO were added into wells to dissolve formazan crystals. After 20 min of incubation at room temperature crystals totally dissolved. Optical density in wells was measured by multiwell spectrophotometer (Labsystems Multiscan PLUS, USA) at $540 \mathrm{~nm}$ [23].

We studied cells sensitivity and cytotoxic effect of NC and its components. NC and DDP were used in doses equal to $\mathrm{IC}_{20}$ (by DDP) for each studied cell line (sensitive and resistant). $\mathrm{Fe}_{3} \mathrm{O}_{4}$ concentration in medium was equal to $12 \mu \mathrm{g} / \mathrm{ml}$ for MCF-7/S and $48 \mu \mathrm{g} / \mathrm{ml}$ for MCF-7/DDP cells, respectively. After addition of these agents into cultivation medium cells were cultivated for 48 hours in standard conditions.

After cultivation we studied expression of endogenous iron metabolism proteins, apoptosis regulators, $\mathrm{CpG}$-sites methylation in promoters of ferritin heavy chains and transferrin receptor 1 genes, pool of reactive oxygen species (ROS), number of cells in apoptosis and necrosis, and expression of miRNA which regulate apoptosis, cell adhesion and activity of ferritin heavy chains.

\subsection{Immunocytochemistry}

The cells for the immunocytochemical analysis were grown on cover glasses, incubated in fixative solution (methanol:acetone $1: 1$ ) during 2 hours at $\mathrm{t}-20^{\circ} \mathrm{C}$, than with $1 \%$ solution of bovine serum albumin (BSA) for 20 minutes. The monoclonal antibodies for defying of proteins were against transferrin receptor 1 (TFR1) (Bioworld Technology, USA), transferrin (Tf), ferritin light chains (FTL) (Abcam, USA), ferritin heavy chains (FTH) (GeneTex, USA), p53, Bcl-2 and Bax (DakoCytomation, Denmark) were applied in standard conditions of cultivation with according to algorithm of methodical approaches [24].

The estimation of results was made with the help of optical microscope $(\times 100$, oil immersion) with usage of classical method of H-Score:

$$
\mathrm{S}=1 \times \mathrm{N}_{1+}+2 \times \mathrm{N}_{2+}+3 \times \mathrm{N}_{3+}
$$

where S-"H-Score" index, $\mathrm{N}_{1+}, \mathrm{N}_{2+}$ and $\mathrm{N}_{3+}$-numbers of cells with low, medium or high expression of the marker [25].

\subsection{Methylation-Specific PCR (MSP)}

Bisulfite conversion involves the deamination of unmodified cytosine residues to uracil under the influence of hydrosulfite ion from water solution of sodium bisulfite. Such treatment doesn't affect 5-mC and in further amplification uracils are amplified as thymines, whereas 5-mC residues get amplified as cytosines. Bisulfite conversion was performed using EZ DNA Methylation Gold-Kit (Zymo Research, USA) according to manufacturer's pro- tocol. Aliquots of bisulfite-modified DNA were stored at $-20^{\circ} \mathrm{C}$ and were used for MSP. Methylation-specific PCR was performed using the standard protocols; primer sequences are available in Table 1.

MSP-mixture contained 12.5 $\mu$ l of Master Mix (Applied Biosystem, USA), $50 \mathrm{pM}$ forward and reverse primers (IDT, USA), $3 \mathrm{ml}$ ( $\sim 50 \mathrm{ng}$ ) of bisulfite-converted DNA and deionized water to a final reaction volume of 25 $\mu 1$. PCR reaction consisted of the following steps: denaturation of DNA at $95^{\circ} \mathrm{C}$ during $10 \mathrm{~min}, 35$ cycles of amplification (denaturation at $95^{\circ} \mathrm{C}$ for $30 \mathrm{~s}$ ), annealing of primers $\left(56^{\circ} \mathrm{C}\right.$ for $\left.20 \mathrm{~s}\right)$, polymerization $\left(72^{\circ} \mathrm{C}\right.$ for $\left.30 \mathrm{~s}\right)$ and final polymerization at $72^{\circ} \mathrm{C}$ for $10 \mathrm{sec}$.

PCR products were analyzed by agarose gel electrophoresis in 1.2\% agarose "Low EEO, Type 1-A" ("Sigma”, USA). Samples were loaded in amount of $6 \mathrm{ml} \mathrm{PCR-}$ product in well for each sample. For electrophoresis was used Tris-acetate buffer (40 mM Tris-acetate, $\mathrm{pH} 8.0$; $1 \mathrm{mM}$ EDTA). After electrophoresis the results was visualized by ethidium bromide, photographed under UV light and evaluated by a computer program TotalLab v2.01.

\subsection{MicroRNA Expression Analysis}

Total RNA extraction from the cells was performed using a commercial set of "Rhibo-zol" (Amplisense, Russia). Concentration of isolated RNA was determined using spectrophotometer "NanoDrop 2000c" (ThermoScientific, USA). Purity of isolated RNA is controlled by $\mathrm{E}_{260} / \mathrm{E}_{280}$ ratio. RNA then was dissolved in TE buffer and stored at $-20^{\circ} \mathrm{C}$.

For the reverse transcriptase PCR (RT-PCR) we used the reaction mixture, listed in Table 2. RT-PCR was performed "Tertsyk" thermocycler ("DNA technology", Russia) using the following reaction parameters (Table 3). After the RT-PCR reaction product was added to a mixture of reagents (Table 4). AmpliTaq Gold Enzyme was activated and PCR was performed (40 cycles, denature-

Table 1. Primer sequences used in MSP.

\begin{tabular}{crc}
\hline Name & Nucleotide sequence & $\begin{array}{c}\text { Final } \\
\text { product size }\end{array}$ \\
\hline FTH_M (forward) & 5'-cgagggtttttagcggtc-3' & $128 \mathrm{bp}$ \\
FTH_M (reverse) & 5'-atctcttataaccgcgtcgac-3' & \\
FTH_U (forward) & 5'-gtgagggtttttagtggtt-3' & \\
FTH_U (reverse) & 5'-aatctcttataaccacatcaac-3' & \\
TFR1_M (forward) & 5'-gtagttgggattataggcgc-3' & \\
TFR1_M (reverse) & 5'-taattaccaaacgcgataactc-3' & \\
TFR1_U (forward) & 5'-tgagtagttgggattataggtgt-3' & \\
TFR1_U (reverse) & 5'-taattaccaaacacaataactcac-3' & \\
\hline
\end{tabular}


Table 2. Composition of the reaction mixture for RT-PCR.

\begin{tabular}{cc}
\hline Components of the reaction mixture & Volume $(\mu \mathrm{L})$ \\
\hline $100 \mathrm{mM}$ dNTP mix & 0.05 \\
Reverse transcriptase multiscribe, $50 \mathrm{U} / \mu \mathrm{L}$ & 0.33 \\
$10 \times$ RT buffer & 0.50 \\
RNAse inhibitor $20 \mathrm{U} / \mu \mathrm{L}$ & 0.06 \\
Nuclease-free water & 1.56 \\
$5 \times$ TaqMan miRNA primer & 1.00 \\
Total RNA sample & 1.50 \\
Total & 5.0 \\
\hline
\end{tabular}

Table 3. Temperature parameters for RT-PCR.

\begin{tabular}{cc}
\hline Temperature $\left({ }^{\circ} \mathrm{C}\right)$ & Time $(\min )$ \\
\hline 16 & 30 \\
42 & 30 \\
85 & 5 \\
4 & $\infty$ \\
\hline
\end{tabular}

Table 4. Composition of the reaction mixture for PCR.

\begin{tabular}{cc}
\hline Reagent & Volume $(\mu \mathrm{L})$ \\
\hline $2 \times$ TaqMan 2 universal PCR master mix, \\
no AmpErase UNG & 10.00 \\
Nuclease-free water & 4.00 \\
$20 \times$ TaqMan MicroRNA assays mix & 1.00 \\
Product from RT reaction & 5.00 \\
Total & 20.00 \\
\hline
\end{tabular}

tion at $95^{\circ} \mathrm{C}$ for $15 \mathrm{sec}$, annealing and extension of primers at $65^{\circ} \mathrm{C}, 60 \mathrm{sec}$ ).

Horizontal gel electrophoresis was performed as described above. The values of miRNA expression were normalized by calculating the miRNA/miRNA-u87 (positive control) expression ratios for each miRNA.

\subsection{Measurement of Intracellular ROS}

CM-H2DCFDA, a lipid soluble membrane permeable dye upon entering cells undergoes deacetylation by intracellular esterases and forms the more hydrophilic, nonfluorescent dye Dichlorodihydrofluorescein (DCFH2). This is subsequently oxidized by ROS with formation of a highly fluorescent oxidation product, Dichlorofluorescein (DCF). The generated fluorescence is directly proportional to the amount of ROS. Fluorescence was analyzed by flow cytometry. The effect of DDP, MF and NC on generation of ROS was measured in MCF-7/S and
MCF-7/DDP cell lines $\left(2.5 \times 10^{5}\right.$ cells $)$. After centrifugation (1500 rpm for 5 minutes) cells were resuspended in PBS, incubated for 30 minutes at $37^{\circ} \mathrm{C}$ with

CM-H2DCFDA (10 mM) for measurement of ROS. Positive control with $25 \mu \mathrm{M} \mathrm{H}_{2} \mathrm{O}_{2}$ was also made (data not presented). Fluorescence was acquired in the log mode and expressed as geometrical mean fluorescence channel (GMean). Acquisition was performed on 10,000 gated events.

\subsection{Measurement of Annexin V Positivity}

Translocation of phosphatidylserine from the inner to the outer leaflet of the plasma membrane occurs during apoptosis and can be assessed by exploiting the high binding affinity of Annexin $\mathrm{V}$, a $\mathrm{Ca}^{2+}$-dependent phospholipid binding protein to phosphatidylserine. To examine whether cell death occurred via apoptosis or necrosis, propidium iodide (PI), a non-permeable stain with affinity towards nucleic acids, which selectively enters necrotic or late apoptotic cells, was used. Therefore, costaining of Annexin V and PI helps discriminate between live cells (PI and Annexin V negative), cells in early apoptosis (Annexin V positive, PI negative), cells undergoing late apoptosis (both Annexin V and PI positive) or necrotic cells (PI positive, Annexin V negative).

For detection of apoptotic cells we used apoptosis detection kit (Annexin V-FITC kit, Beckman Coulter, USA). Briefly, MCF/S and MCF/DDP $\left(2.5 \times 10^{5} / \mathrm{ml}\right)$ were incubated with DDP, MF and NC as described above. After two washes, cells were resuspended in Annexin $\mathrm{V}$ binding buffer $(10 \mathrm{mM}$ HEPES/NaOH, pH 7.4, $140 \mathrm{mM} \mathrm{NaCl}$, $2.5 \mathrm{mM} \mathrm{CaCl}_{2}$ ) and Annexin V-FITC was added according to the manufacturers' instructions. The cells were incubated for 10 minutes in the dark at $37^{\circ} \mathrm{C}$ and just $5 \mathrm{~min}$ prior to acquisition, PI $(0.1 \mathrm{mg} / \mathrm{ml})$ was added and cells were washed and placed then in a flow cytometer.

\subsection{Statistical Processing of the Results}

Statistical processing of the obtained results was carried out with the help of mathematical program of medical and biological statistics STATISTICA 6.0 and in the environment of Microsoft Excel. Calculation and comparison of the significance of differences between the average values was carried out with usage of Student's t-criterion. Differences were considered significant with the probability not less than $95 \%(\mathrm{P}<0.05)$.

\section{Results}

Currently it has been clearly demonstrated that the effectiveness of most ATDR depends not only on the depth of DNA violation or other cellular targets damages, but it is also associated with the apoptotic program induction, cells' oxidative stress, impaired structural and functional 
state of their cytoskeleton, and changes in transport and metabolic processes, including iron metabolism. At the same time one of the biggest obstacles in the treatment of patients with malignant tumors, including breast cancer, is resistance to ATDR. According to the literature data and the results of our research, the development of resistance to cytostatic agents is accompanied by changes in the level of apoptosis regulatory-proteins, proliferation, transport, detoxication system, intercellular adhesion and receptor status [26].

At the same time, it was shown that the formation of the phenotype of drug resistance to DDP is accompanied by impaired protein metabolism of endogenous iron: increased expression of regulatory-proteins of transmembrane transport (TFR1), cell influx of iron (Tf) and ferritin (FTL, FTH) as a protein of intracellular iron storage and deposition (Figure 1, Table 5). Development of resistance to anticancer drugs also was accompanied by the shift of ferritin's light chains from cytoplasm to cell nucleus.

It should be noted that the development of DDP-resistance in MCF-7 cells led to the increase of TFR1 expression by $200 \%$, Tf level more than $80 \%$, and FTL and FTH-by $50 \%$ and $75 \%$, respectively.

Based on the data presented above, and in contrast to the searching for binding factors of $\mathrm{Fe}$ ions in tumor cells, we investigated the anti-tumor effect of $\mathrm{NC}$ containing DDP and mixture $\mathrm{Fe}_{2} \mathrm{O}_{3}-\mathrm{Fe}_{3} \mathrm{O}_{4}$ nanoparicles, as delivery vector for cytostatic. To elucidate the possible mechanisms of death of original and resistant cells caused by $\mathrm{NC}$ and its components we held a wide range of studies of molecular genetic and epigenetic markers that might be associated with iron regulatory-proteins and survival of MCF-7 and MCF-7/DDP cells.

In our previous studies with use of light and electron microscopy we showed that $\mathrm{MF}$ and $\mathrm{NC}$ were able to penetrate and accumulate in both MCF-7/S and MCF-7/DDP cells [26] using histochemical staining with potassium ferro- and ferricyanide. We found that $\mathrm{NC}$ incorporation into $\mathrm{MCF}-7 / \mathrm{DDP}$ cells compared to $\mathrm{MCF}-7 / \mathrm{S}$ cells is much more active. Cytomorphology and electron microscopy of resistant cells with high levels of accumulated NC showed its higher cytotoxic effects in particular dystrophy, necrobiosis, necrosis and apoptosis.

It was established that cultivation of original and resistant MCF-7 cells with MF and NC was accompanied by

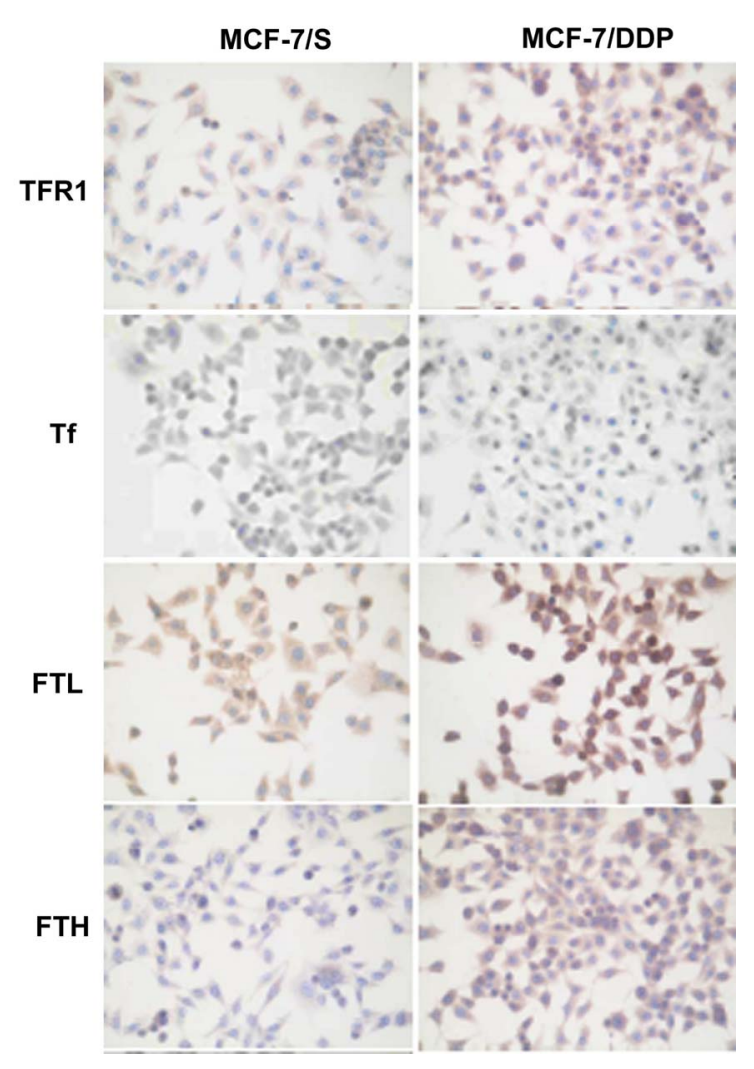

Figure 1. Expression of iron metabolism proteins in MCF-7/S and MCF-7/DDP cells.

Table 5. Expression of iron-regulatory proteins in the MCF-7/S and MCF-7/DDP cells.

\begin{tabular}{|c|c|c|c|c|c|}
\hline \multirow{2}{*}{ Marker } & \multirow{2}{*}{ Cell line } & \multicolumn{4}{|c|}{ Expression of studied markers, $\mathrm{H}$-score values } \\
\hline & & Control & MF & DDP & $\mathrm{NC}$ \\
\hline \multirow{2}{*}{ TFR1 } & $\mathrm{MCF}-7 / \mathrm{S}$ & $72 \pm 1.8$ & $101 \pm 3.6$ & $72 \pm 1.6$ & $110 \pm 3.5$ \\
\hline & MCF-7/DDP & $215 \pm 5.5$ & $235 \pm 3.6$ & $215 \pm 3.4$ & $288 \pm 3.5$ \\
\hline \multirow{2}{*}{$\mathrm{Tf}$} & $\mathrm{MCF}-7 / \mathrm{S}$ & $160 \pm 5.4$ & $184 \pm 2.5$ & $156 \pm 2.4$ & $197 \pm 3.6$ \\
\hline & MCF-7/DDP & $293 \pm 6.0$ & $296 \pm 3.5$ & $293 \pm 4.3$ & $299 \pm 0.3$ \\
\hline \multirow{2}{*}{ FTL } & $\mathrm{MCF}-7 / \mathrm{S}$ & $195 \pm 4.5$ & $209 \pm 2.8$ & $193 \pm 3.5$ & $214 \pm 3.1$ \\
\hline & MCF-7/DDP & $296 \pm 2.8$ & $299 \pm 2.8$ & $294 \pm 5.8$ & $299 \pm 0.5$ \\
\hline \multirow{2}{*}{ FTH } & $\mathrm{MCF}-7 / \mathrm{S}$ & $125 \pm 2.7$ & $160 \pm 3.2$ & $125 \pm 2.5$ & $169 \pm 2.0$ \\
\hline & MCF-7/DDP & $220 \pm 6.1$ & $277 \pm 3.6$ & $223 \pm 4.3$ & $298 \pm 2.0$ \\
\hline
\end{tabular}


significant changes in the expression of the investigated iron regulatory-proteins (Table 5). Herewith, the most significant changes in original cells were observed in the levels of Tf and TFR1 expression, as well as FTL and FTH. Under the influence of MF and NC TFR1 expression level increased by $40.3 \%$ and $52.8 \%$, and the expression level of FTH - by $28.0 \%$ and $35.2 \%$, respectively. Significant Tf expression increase in sensitive cells was observed only under NC treatment. In resistant cells the most significant changes were found in TFR1 expression under the influence of $\mathrm{NC}$ and in FTH expression when MF and NC have been used (Table 5). It is noteworthy that the level of FTL expression under the influence of MF and $\mathrm{NC}$ did not change significantly in original and resistant cells.

At the same time we found that under the influence of $\mathrm{NC}$ and its components the disturbances of epigenetic regulation of some regulatory genes of endogenous iron metabolism occur. It was shown that cultivation of original and resistant MCF-7 cells with DDP, MF and NC was accompanied by hypomethylation of CpG-sites of TFR1 gene promoters and hypermethylation of CpG-sites of FTH gene promoters (Figure 2).

Free intracellular iron is known to be associated with free radicals generation. So we had investigated alterations of ROS level in parental and DDP resistant cell lines after the treatment with $\mathrm{NC}$ and its derivatives. It should be stressed here that ROS could induce oncogenesis in normal cells and apoptosis in cancer cells.

Significance of ROS activity isn't definitely characterized to date. Development of DDP resistance is associated with 1.83-fold free oxygen level elevation (Table 6, Figure 3) and could be associated with failure of antioxidant system or rise of content of iron keeping proteins.

Significant increase of free oxygen radical activity was detected after NC treatment in MCF-7 cells (by 15\%) and MCF-7/DDP (by 25\%). Elevation of ROS level after NC treatment could be important factor on the one hand in DDP antitumor activity increase and on the other hand

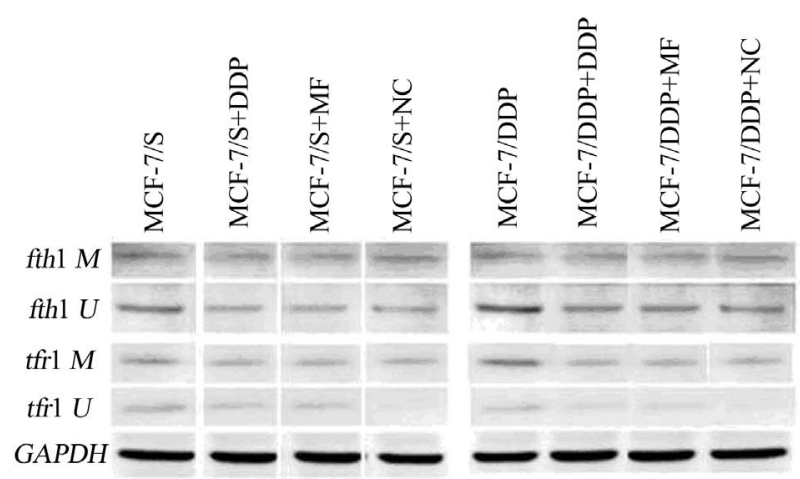

Figure 2. Peculiarities of methylation CpG-sites in the genes promoters of FTH and TFR1 in original and resistant MCF-7 cells under the influence of MF, DDP and NC.
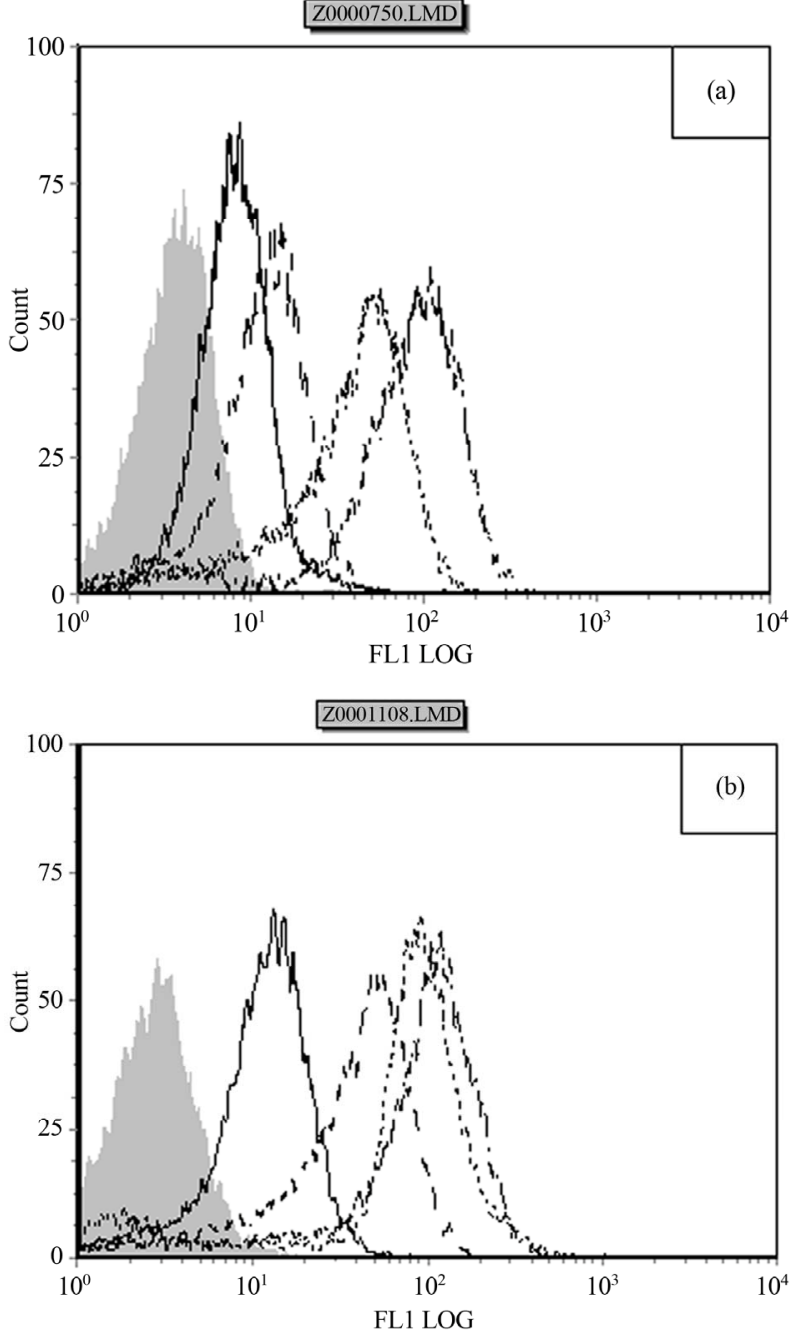

Figure 3. Flow cytometry study of ROS expression in (a) MCF-7/S and (b) MCF-7/DDP cells. Filled histogram is isotype control, ROS in control cells, ROS in cells treated with DDP, MF and NC.

Table 6. Flow cytometry studies of intracellular ROS (GMean values).

\begin{tabular}{ccccc}
\hline \multirow{2}{*}{ Cell lines } & \multicolumn{4}{c}{ ROS level } \\
\cline { 2 - 5 } & Control & DDP & MF & NC \\
\hline MCF-7/S & $7.27 \pm 0.65$ & $8.61 \pm 1.55$ & $13.88 \pm 1.96$ & $35.18 \pm 5.02$ \\
MCF-7/DDP & $13.30 \pm 1.24$ & $18.96 \pm 2.48$ & $35.48 \pm 3.45$ & $53.67 \pm 4.44$ \\
\hline
\end{tabular}

could be a key mechanism in overcoming DDP resistance DDP is known to induce tumor cell death by the apoptotic mechanism. Meanwhile last year's investigations suggest that NCs of different origin can also induce apoptosis in tumor cells. Thus next direction of our experiments was to elucidate the $\mathrm{NC}$ role in apoptosis initiation in MCF-7/S and MCF-7/DDP cells.

Table 7 and Figure 4 show that DDP induced apop- 

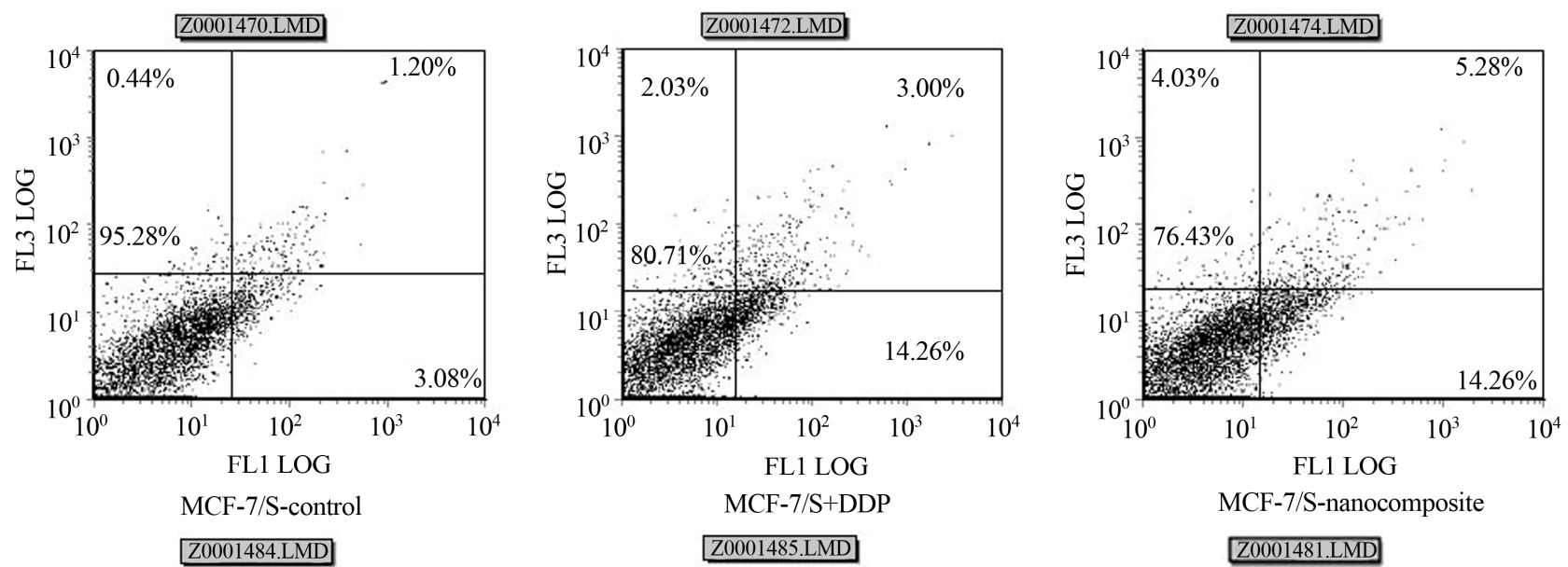

MCF-7/S-control
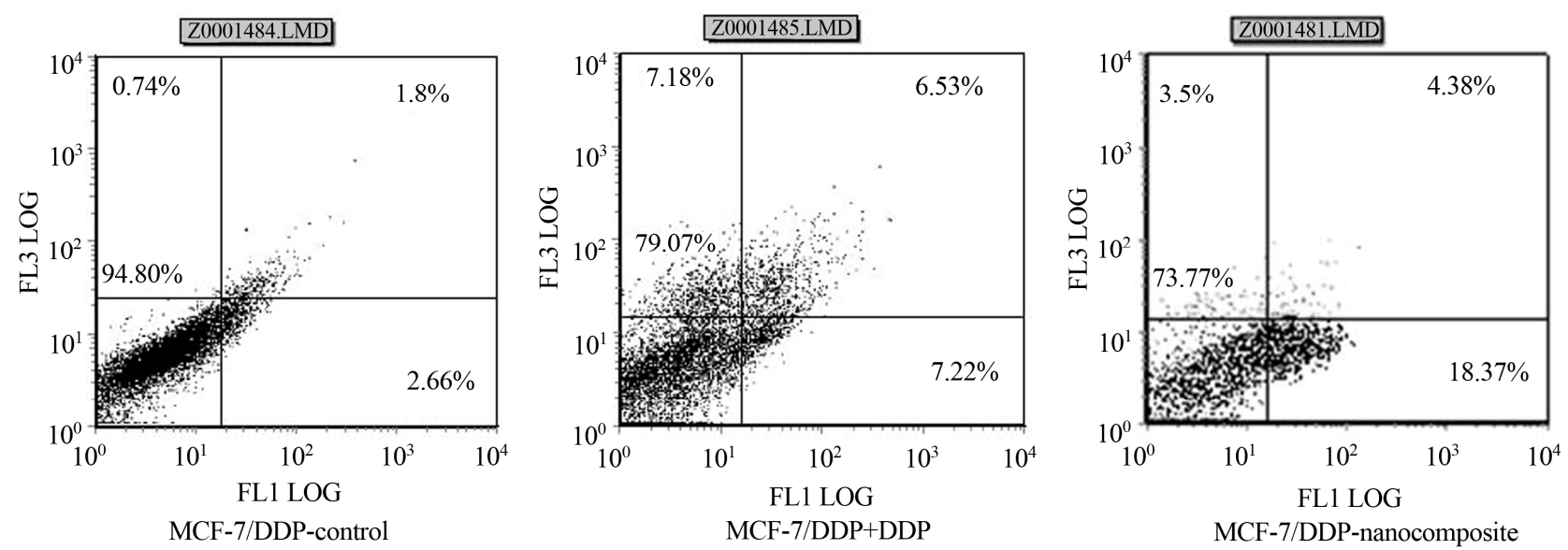

Figure 4. Changes in percent of MCF-7/S (top) and MCF-7/DDP cells (bottom) in necrosis and apoptosis after treatment with DDP and NC.

Table 7. Changes in percentage of MCF-7/S and MCF-7/DDP cells in necrosis and apoptosis after treatment with DDP, MF and NC.

\begin{tabular}{cccccc}
\hline \multirow{3}{*}{ Cell lines } & Parameters & \multicolumn{3}{c}{ Studied factors and number of cells in apoptosis and necrosis (\%) } \\
\cline { 3 - 5 } & & Control & DDP & MF & NC \\
\hline \multirow{3}{*}{ MCF-7/S } & Live cells & $95.28 \pm 1.44$ & $80.71 \pm 2.35$ & $93.46 \pm 2.66$ & $76.43 \pm 3.44$ \\
& Necrosis & $0.44 \pm 0.06$ & $2.03 \pm 0.09$ & $2.35 \pm 0.12$ & $4.03 \pm 0.21$ \\
& Apoptosis & $4.28 \pm 0.53$ & $17.26 \pm 1.06$ & $4.19 \pm 0.61$ & $19.54 \pm 1.46$ \\
& Live cells & $97.80 \pm 1.56$ & $79.07 \pm 1.96$ & $89.83 \pm 1.65$ & $73.77 \pm 2.65$ \\
MCF-7/DDP & Necrosis & $0.74 \pm 0.08$ & $7.18 \pm 0.11$ & $3.96 \pm 0.31$ & $3.50 \pm 0.74$ \\
& Apoptosis & $4.46 \pm 0.63$ & $19.75 \pm 1.85$ & $5.21 \pm 0.55$ & $22.73 \pm 2.77$ \\
\hline
\end{tabular}

tosis in $17.3 \%$ and necrosis in $2 \%$ of $\mathrm{MCF}-7 / \mathrm{S}$ cells. Quantity of apoptotic and necrotic MCF-7 cells after MF treatment was at the level of control cells. NC induced increase of number of cells in apoptosis and necrosis to $19.9 \%$ and $3.5 \%$ for $\mathrm{MCF}-7 / \mathrm{S}$ cell line. MF treatment slightly increased percent of apoptotic and necrotic MCF-7/DDP cells. It must be noted, that NC treatment did not reduce but, on the contrary, increased rates of apoptotic and necrotic cells in sensitive and resistant to DDP cell lines. Efficiency of apoptosis induction with antitumor drugs is known to be dependent on the expression level of a number of key regulatory molecules and the degree of activity of signaling cascades formation. So the next stage of our research was to determine the expression level of apoptosis regulating proteins in human breast cancer cell lines MCF-7/S and MCF-7/DDP.

Previously presented data [27] showed that generation of DDP resistance in MCF-7/DDP cell line is accompanied by slight decrease of p53 expression and significant changes in expression of antiapoptotic proteins Bcl-2 and Bax.

However, recently p53 subunit (R2), which has $\mathrm{Fe}$ 
binding sites and provides nucleotides for DNA reparation was discovered [28-30]. Thus, investigations of modification role of exogenous iron source in key links of apoptotic program arouse scientific interest.

While studying changes of expression of proteins, associated with apoptosis, we found out that $\mathrm{NC}$ influences expression of $\mathrm{p} 53, \mathrm{Bcl}-2$ and Bax proteins (Table 8). In parental MCF-7 cells DDP and NC induced decrease of Bcl-2 expression on $23.5 \%$ and on $22.6 \%$, respectively, and increased expression of Bax on $14.9 \%$ and $24.3 \%$ respectively. In DDP resistant cells MCF-7/DDP similar changes in proteins expression were detected. However, it is important to note that NC significantly increased expression of proapoptotic protein p53 in MCF-7/DDP cells. Obtained data indicate that $\mathrm{NC}$ is able to initiate apoptotic program not only in $\mathrm{MCF}-7 / \mathrm{S}$ cells, but more significantly in MCF-7/DDP cells due to reduction of antiapoptotic protein Bcl-2 expression and elevation of proapoptotic p53 and Bax expression. Our results indicate the impact of exogenous iron, which is the part of NC, on the changes of molecular genetic markers expression level, which determines sensitivity to apoptosis induction, the degree of adhesion and invasion of MCF-7/S and MCF-7/DDP cells. At the same time, in the available literature there are no data on the influence of exogenous sources of iron on expression of miRNAs.

In particular, our attention was attracted by miR-34 and miR-200b, which are involved in the regulation of apoptosis, cell-cell adhesion, invasion and activity of ferritin heavy chains gene [12,31].

We have found that another link in the chain of mechanisms, that causes the increase in the percentage of cells dying by apoptosis in sensitive and resistant MCF-7 cells during their cultivation with DDP, MF and NCs, is the miR-34 and miR-200b expression elevation (Figure 5).

Obtained results are also evidence of increased sensitivity of the investigated cells to antitumor drugs, which is particularly important fact concerning the resistant cells.

\section{Discussion}

So, in vitro we showed genetic and epigenetic mecha- nisms of action of NC of MF and DDP. NC caused elevation of number of cells in apoptosis in sensitive and especially resistant MCF-7 cells compared to DDP alone. It was proved that impact of $\mathrm{NC}$ on $\mathrm{MCF}-7 / \mathrm{S}$ and MCF-7/DDP cells caused more significant changes in $\mathrm{p} 53$, Bcl-2 and Bax expression, which regulated apoptosis.

We also suggested that changes in endogenous iron homeostasis and activation of free radical processes caused significant impact on apoptosis because of oxidative stress development.

It is known that elevation of iron concentration in the cytoplasm might cause oxidative stress due to ROS generation in Fenton reactions [9]. DDP itself is also able to cause ROS generation by induction of NADPH oxidadases expression [31]. In our study we noted elevation of ROS content in both cell lines after impact of NC.

It is also known that FTH expression during oxidative stress increased by IRE/IRP system to transfer iron ions into the bound state and decreased number of ROS generation sites [32].

IRP usually connects with IRE on mRNA by SHgroups in cysteine residues. It was shown that accumula-
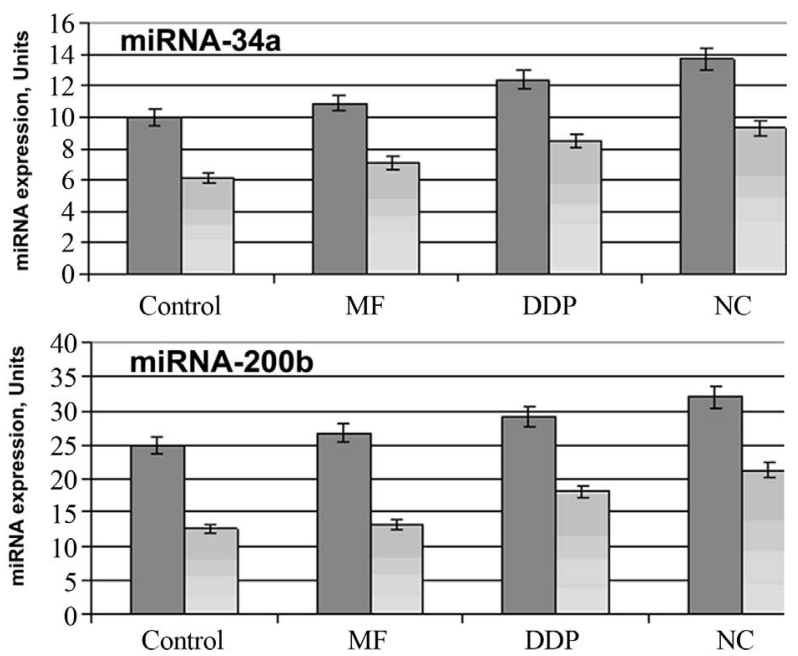

Figure 5. miRNA-34a and miRNA-200b expression in MCF-7/S cells (dark) and MCF-7/DDP cells (light) after impact of MF, DDP and NC.

Table 8. Changes in expression of proteins which regulate apoptosis in MCF-7/S and MCF-7/DDP cells after impact of NC and its components.

\begin{tabular}{|c|c|c|c|c|c|}
\hline \multirow{2}{*}{ Marker } & \multirow{2}{*}{ Cell lines } & \multicolumn{4}{|c|}{ Studied markers expression (H-score values) } \\
\hline & & Control & $\mathrm{MF}$ & DDP & $\mathrm{NC}$ \\
\hline \multirow{2}{*}{ p53 } & $\mathrm{MCF}-7 / \mathrm{S}$ & $183 \pm 4.7$ & $180 \pm 3.6$ & $208 \pm 4.6$ & $179 \pm 2.6$ \\
\hline & MCF-7/DDP & $164 \pm 4.1$ & $135 \pm 2.6$ & $166 \pm 3.9$ & $180 \pm 4.1$ \\
\hline \multirow{2}{*}{ Bcl-2 } & $\mathrm{MCF}-7 / \mathrm{S}$ & $179 \pm 2.9$ & $169 \pm 2.3$ & $137 \pm 2.5$ & $126 \pm 3.0$ \\
\hline & MCF-7/DDP & $36 \pm 0.9$ & $36 \pm 2.5$ & $35 \pm 2.5$ & $18 \pm 1.7$ \\
\hline \multirow{2}{*}{ Bax } & $\mathrm{MCF}-7 / \mathrm{S}$ & $181 \pm 2.4$ & $178 \pm 2.1$ & $208 \pm 2.8$ & $225 \pm 3.1$ \\
\hline & MCF-7/DDP & $62 \pm 1.4$ & $62 \pm 2.8$ & $64 \pm 3.4$ & $121 \pm 2.7$ \\
\hline
\end{tabular}




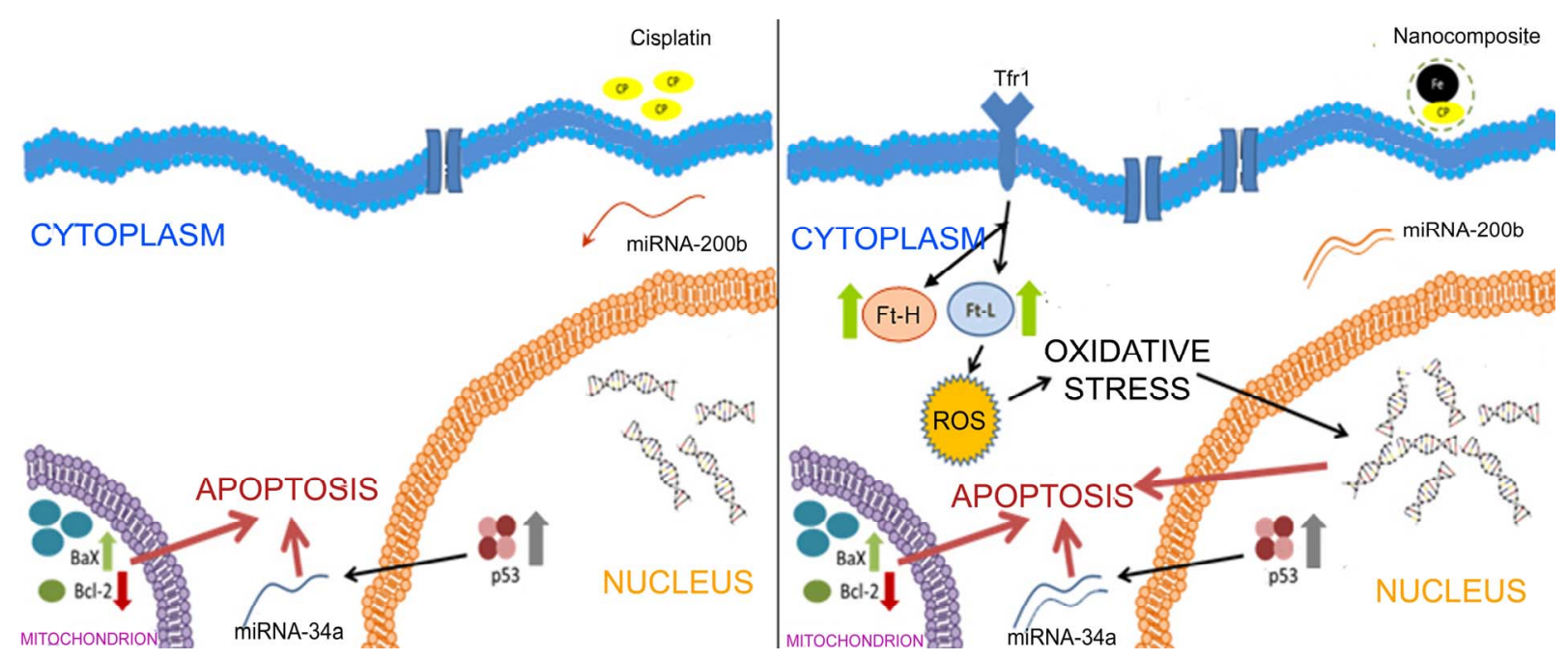

Figure 6. Schematic illustration of mechanisms of action of DDP and NC (based on ferromagnetic and DDP).

tion of ROS-generating substances (ATDR, iron-containing nanoparticles) by cells caused oxidation of these residues, formation of disulfide bonds and resulted in disturbances in protein conformation and interaction with mRNA causing increase of TFR1 expression [33]. Such phenomenon of sinchronous changes in FTH and TFR1 expression as a result of oxidative stress was observed by different groups of scientists on different cell lines [34, 35].

On the other hand, we suggest that there is another mechanism of TFR1 expression increase associated with hypomethylation of its gene. It is known that under oxidative stress DNA methyltransferases 1 and $3 \mathrm{~B}$ are able to change their localization in chromatin causing changes in global methylation patterns [36]. This mechanism probably is the basis of increase of TFR1 expression.

We also showed that NC impact resulted into significant changes of expression of miRNA-34a and miRNA200b, which regulated apoptosis, cell adhesion, invasion and activity of ferritin heavy chains gene.

Thus, the use of NC containing DDP and ferromagnetic as exogenous source of $\mathrm{Fe}$ ions causes changes of endogenous iron levels in sensitive and resistant cells allowing to increase specific activity of cytostatic agent and overcome factors, which promote MDR development (Figure 6).

\section{REFERENCES}

[1] V. Almendro, A. Marusyk and K. Polyak, "Cellular Heterogeneity and Molecular Evolution in Cancer," Annual Review of Pathology_Mechanisms of Disease, Vol. 8, 2013, pp. 277-302.

[2] M. H. Barcellos-Hoff, "Does Microenvironment Contribute to the Etiology of Estrogen Receptor-Negative Breast Cancer?" Clinical Cancer Research, Vol. 19, No. 3, 2013, pp. 541-548.
http://dx.doi.org/10.1158/1078-0432.CCR-12-2241

[3] V. F. Chekhun, S. D. Sherban and Z. D. Savtsova, "Tumor Heterogeneity-Dynamical State," Oncology, Vol. 14, No. 1, 2012, pp. 4-12.

[4] V. F. Chekhun, "From System Cancer Biology to Personalized Treatment," Oncology, Vol. 14, No. 2, 2012, pp. 84-88.

[5] N. A. Saunders, F. Simpson, E. W. Thompson, M. M. Hill, L. Endo-Munoz, G. Leggatt, R. F. Minchin and A. Guminski, "Role of Intratumoural Heterogeneity in Cancer Drug Resistance: Molecular and Clinical Perspectives," EMBO Molecular Medicine, Vol. 4, No. 8, 2012, pp. 675684. http://dx.doi.org/10.1002/emmm.201101131

[6] T. V. Bagnyukova, I. P. Pogribny and V. F. Chekhun, "MicroRNAs in Normal and Cancer Cells: A New Class of Gene Expression Regulators," Experimental Oncology, Vol. 28, No. 4, 2006, pp. 263-269.

[7] K. R. Kutanzi, O. V. Yurchenko, F. A. Beland, V. F. Checkhun and I. P. Pogribny, "MicroRNA-Mediated Drug Resistance in Breast Cancer," Clinical Epigenetics, Vol. 2, No. 2, 2011, pp. 171-185.

http://dx.doi.org/10.1007/s13148-011-0040-8

[8] T. A. Farazi, J. I. Hoell, P. Morozov and T. Tusch, "MicroRNAs in Human Cancer," Advances in Experimental Medicine and Biology, Vol. 774, 2013, pp. 1-20. http://dx.doi.org/10.1007/978-94-007-5590-1_1

[9] S. Toyokuni, "Iron and Carcinogenesis: From Fenton Reaction to Target Genes," Redox Report, Vol. 7, No. 4, 2002, pp. $189-197$.

http://dx.doi.org/10.1179/135100002125000596

[10] P. Karihtala and Y. Soini, "Reactive Oxygen Species and Antioxidant Mechanisms in Human Tissues and Their Relation to Malignancies," APMIS, Vol. 115, No. 2, 2007, pp. 81-103.

http://dx.doi.org/10.1111/j.1600-0463.2007.apm 514.x

[11] H. Wiseman and B. Halliwell, "Damage to DNA by Reactive Oxygen and Nitrogen Species: Role in Inflammatory Disease and Progression to Cancer," Biochemical Journal, Vol. 313, No. 1, 1996, pp. 17-29. 
[12] S. I. Shpyleva, V. P. Tryndyak, O. Kovalchuk, A. Starlard-Davenport, V. F. Chekhun, F. A. Beland and I. P. Pogribny, "Role of Ferritin Alterations in Human Breast Cancer Cells," Breast Cancer Research and Treatment, Vol. 126, No. 1, 2011, pp. 63-71. http://dx.doi.org/10.1007/s10549-010-0849-4

[13] K. Fan, L. Gao and X. Yan, "Human Ferritin for Tumor Detection and Therapy," Wiley Interdisciplinary Reviews Nanomedicine and Nanobiotechnology, Vol. 5, No. 4, 2013, pp. 287-298. http://dx.doi.org/10.1002/wnan.1221

[14] C. Datz, T. K. Felder, D. Niederseer and E. Aigner, "Iron Homeostasis in the Metabolic Syndrome," European Journal of Clinical Investigation, Vol. 43, No. 2, 2013, pp. 215-224. http://dx.doi.org/10.1111/eci.12032

[15] E. C. Theil, R. K. Behera and T. Tosha, "Ferritins for Chemistry and for Life," Coordination Chemistry Reviews, Vol. 257, No. 2, 2013, pp. 579-586. http://dx.doi.org/10.1016/j.ccr.2012.05.013

[16] M. Geppert, M. C. Hohnholt, S. Nürnberger and R. Dringen, "Ferritin Up-Regulation and Transient ROS Production in Cultured Brain Astrocytes after Loading with Iron Oxide Nanoparticles," Acta Biomaterialia, Vol. 8, No. 10, 2012, pp. 3832-3839. http://dx.doi.org/10.1016/j.actbio.2012.06.029

[17] V. F. Chekhun, N. Yu. Lukianova and N. O. Bezdenezhnykh, "Features of Iron Metabolism Regulatingproteins Expression in Sensitive and Resistant to Antitumor Drugs Breast Cancer Cells in Vitro," Clinical Oncology (SE), Proceedings of XII Ukrainian Oncologists Meeting, Sudak, 2011, p. 227.

[18] N. Kikyo, M. Suda, N. Kikyo, K. Hagiwara, K. Yasukawa, M. Fujisawa, Y. Yazaki and T. Okabe, "Purification and Characterization of a Cell Growth Factor from a Human Leukemia Cell Line: Immunological Identity with Ferritin," Cancer Research, Vol. 54, No. 1, 1994, pp. 268271.

[19] E. Laqué-Rupérez, M. J. Ruiz-Gómez, L. de la Peña, L. Gil and M. Martínez-Morillo, "Methotrexate Cytotoxicity on MCF-7 Breast Cancer Cells Is Not Altered by Exposure to $25 \mathrm{~Hz}, 1.5 \mathrm{mT}$ Magnetic Field and Iron (III) Chloride Hexahydrate," Bioelectrochemistry, Vol. 60, No. 1-2, 2003, pp. 81-86. http://dx.doi.org/10.1016/S1567-5394(03)00054-9

[20] J. F. Head, F. Wang and R. L. Elliott, "Antineoplastic Drugs That Interfere with Iron Metabolism in Cancer Cells," Advances in Enzyme Regulation, Vol. 37, 1997, pp. 147-169. http://dx.doi.org/10.1016/S0065-2571(96)00010-6

[21] S. V. Torti and F. M. Torti, "Cellular Iron Metabolism in Prognosis and Therapy of Breast Cancer," Critical Reviews in Oncogenesis, Vol. 18, No. 5, 2013, pp. 435-448. http://dx.doi.org/10.1615/CritRevOncog.2013007784

[22] J. L. Heath, J. M. Weiss, C. P. Lavau and D. S. Wechsler, "Iron Deprivation in Cancer-Potential Therapeutic Implications," Nutrients, Vol. 5, No. 8, 2013, pp. 2836-2859. http://dx.doi.org/10.3390/nu5082836

[23] M. Niks and M. Otto, "Towards an Optimized MTT Assay," Journal of Immunological Methods, Vol. 130, No. 1, 1990, pp. 149-151.

\section{http://dx.doi.org/10.1016/0022-1759(90)90309-J}

[24] Y. L. Chao, C. R. Shepard and A. Wells, "Breast Carcinoma Cells Re-Express E-Cadherin during Mesenchymal to Epithelial Reverting Transition," Molecular Cancer, Vol. 9, No. 1, 2010, pp. 179-197. http://dx.doi.org/10.1186/1476-4598-9-179

[25] R. A. McCelland, D. Wilson and R. Leake, "A Multicentre Study into the Reliability of Steroid Receptor Immunocyto-Chemical Assay Quantification," European Journal of Cancer, Vol. 27, 1991, pp. 711-715. http://dx.doi.org/10.1016/0277-5379(91)90171-9

[26] V. F. Chekhun, O. V. Yurchenko, L. A. Naleskina, D. V. Demash, N. Yu. Lukianova and Yu. V. Lozovska, "In Vitro Modification of Cisplatin Cytotoxicity with Magnetic Fluid," Experimental Oncology, Vol. 35, No. 1, 2013, pp. 15-19.

[27] N. Yu. Lukyanova, N. V. Rusetskaya and N. A. Tregubova, "Molecular Profile and Cell Cycle in MCF-7 Cells Resistant to Cisplatin and Doxorubicin," Experimental Oncology, Vol. 31, No. 2, 2009, pp. 87-92.

[28] A. Jordan and P. Reichard, "Ribonucleotide Reductases," Annual Review of Biochemistry, Vol. 67, 1998, pp. 71-98. http://dx.doi.org/10.1146/annurev.biochem.67.1.71

[29] H. Tanaka, H. Arakawa, T. Yamaguchi, K. Shiraishi, S. Fukuda, K. Matsui, Y. Takei and Y. Nakamura, "A Ribonucleotide Reductase Gene Involved in a p53-Dependent Cellcycle Checkpoint for DNA Damage," Nature, Vol. 404, 2000, pp. 42-49. http://dx.doi.org/10.1038/35003506

[30] D. S. Byun, K. S. Chae, B. K. Ryu, M. G. Lee and S. G. Chi, "Expression and Mutation Analyses of P53R2, a Newly Identified p53 Target for DNA Repair in Human Gastric Carcinoma," International Journal of Cancer, Vol. 98, No. 5, 2002, pp. 718-723. http://dx.doi.org/10.1002/ijc.10253

[31] N. Yu. Lukianova, L. A. Naleskina, N. O. Bezdenezhnykh, L. M. Kunskaya, D. V. Demash, Yu. V. Yanish, I. M. Todor and V. F. Chekhun, "Reactive Changes of Cytophysiological Properties, Molecular-Biological Profile and Functional Metabolic Status of Cells in Vitro with Different Sensitivity to Cytostatic Agents under the Influence of Magnetic Fluid," Journal of Cancer Research, Vol. 1, No. 1, 2013, pp. 7-14. http://dx.doi.org/10.11648/j.crj.20130101.12

[32] H.-J. Kim, J.-H. Lee, S.-J. Kim, G. S. Oh, H.-D. Moon, K.-B. Kwon, C. Park, B. H. Park, H.-K. Lee, S.-Y. Chung, R. Park and H.-S. So, "Roles of NADPH Oxidases in Cisplatin-Induced Reactive Oxygen Species Generation and Ototoxicity," The Journal of Neuroscience, Vol. 30, No. 11, 2010, pp. 3933-3946. http://dx.doi.org/10.1523/JNEUROSCI.6054-09.2010

[33] A. Cozzi, B. Corsi, S. Levi, P. Santambrogio, G. Biasiotto and P. Arosi, "Analysis of the Biologic Functions of $\mathrm{H}$ and L-Ferritins in HeLa Cells by Transfection with siRNAs and cDNAs: Evidence for a Proliferative Role of L-Ferritin," Blood, Vol. 103, No. 6, 2004, pp. 2377-2383. http://dx.doi.org/10.1182/blood-2003-06-1842

[34] X. Xu, H. L. Persson and D. R. Richardson, "Molecular Pharmacology of the Interaction of Anthracyclines with 
Iron," Molecular Pharmacology, Vol. 68, No. 2, 2005, pp. 261-271.

[35] E. Pawelczyk, A. S. Arbab, S. Pandit, E. Hu and J. A. Frank, "Expression of Transferrin Receptor and Ferritin Following Ferumoxides-Protamine Sulfate Labeling of Cells: Implications for Cellular Magnetic Resonance Imaging," NMR in Biomedicine, Vol. 19, 2006, pp. 581-592. http://dx.doi.org/10.1002/nbm.1038
[36] H. M. O'Hagan, W. Wang, S. Sen, C. D. Shields, S. S. Lee, Y. W. Zhang, E. G. Clements, Y. Cai, L. Van Neste, H. Easwaran, R. A. Casero, C. L. Sears and S. B. Baylin, "Oxidative Damage Targets Complexes Containing DNA Methyltransferases, SIRT1, and Polycomb Members to Promoter CpG Islands," Cancer Cell, Vol. 20, No. 5, 2011 , pp. 606-619. http://dx.doi.org/10.1016/j.ccr.2011.09.012 